\title{
Implementasi Kebijakan Penataan Pedagang Kaki Lima di Kawasan Kota Tua Jakarta
}

\author{
Yayat Sujatna \\ STIE Ahmad Dahlan Jakarta \\ yayatsujatna@gmail.com
}

\begin{abstract}
Jakarta Old Town is one of historical tourism attraction destination which located in Kota, Jakarta. Currently, the DKI government is taking seriously the revitalization in the area. As the increase of tourists' visit in the area impacts the number of street vendors in the area, DKI government as the one that responsible of cleanliness and safety, starts to take action by issuing regulation to restructure and control the street vendors, socially and economically, and guaranty public interests. The aim of the study was to describe, analyze the policy and its implementation and obstacles in restructuring the street vendor in the area. The method used for this study was descriptive-qualitative. The study showed that the implementation of street vendors restructuring policy was implemented successfully and involved many stakeholders.
\end{abstract}

Keywords: Policy implementation; restructuring; street vendors.

\begin{abstract}
Abstrak
Kota Tua Jakarta merupakan salah satu destinasi wisata bersejarah yang terletak di Kota, Jakarta. Pemerintah Provinsi DKI Jakarta saat ini sedang melakukan revitalisasi di kawasan tersebut. Ramainya kunjungan wisatawan baik lokal maupun manca Negara ke Kota Tua Jakarta berdampak pada banyaknya pedagang kaki lima yang berdagang atau membuka lapak usaha di kawasan tersebut. Hal ini mendorong Pemprov DKI Jakarta untuk mengambil kebijakan dalam penataan dan pemberdayaan pedagang kaki lima di Kawasan Kota Tua Jakarta agar keberadaan mereka tidak mengganggu kepentingan publik namun di sisi lain pemberdayaan ekonomi bagi para pedagang kaki lima juga dapat berjalan. Tujuan penelitian ini adalah untuk mendeskripsikan dan menganalisis kebijakan dan implementasinya serta kendala yang dihadapi dalam penataan pedagang kaki lima di Kawasan Kota Tua Jakarta. Penelitian ini menggunakan metode penelitian kualitatif deskriptif. Hasil penelitian menunjukan bahwa Implementasi kebijakan penataan pedagang kaki lima di Kota Tua merupakan successful implementation dan melibatkan banyak stakeholders.
\end{abstract}

Kata Kunci: implementasi kebijakan; penataan; pedagang kaki lima. 


\section{A. PENDAHULUAN}

Kota Tua Jakarta merupakan salah satu destinasi wisata bersejarah yang terletak di Kota Jakarta. Pemerintah Provinsi DKI Jakarta saat ini sedang gencar-gencarnya melakukan revitalisasi di kawasan tersebut. Kawasan yang dijuluki dengan Permata Asia ini menyimpan banyak cerita sejarah di dalamnya. Salah satu gedung bersejarah yang ada di Kota Tua Jakarta adalah Staadhuis atau Balai Kota yang dibangun pertama kali pada tahun 1620 oleh Gubernur Jenderal Jan Pieterzoen Coen. Saat ini gedung tersebut dikenal dengan Museum Sejarah atau Museum Fatahillah dan dilindungi keberadaannya oleh Pemerintah Pusat dan Pemerintah Provinsi DKI Jakarta. Museum Fatahillah memiliki taman seluas kurang lebih $10.000 \mathrm{~m}^{2}$ yang saat ini taman tersebut berfungsi sebagai area public space yang sering digunakan juga sebagai tempat pementasan seni atau acara-acara yang dapat dinikmati oleh masyarakat umum.

Ramainya kunjungan wisatawan baik lokal maupun manca negara ke Kota Tua Jakarta berdampak pada banyaknya pedagang kaki lima yang berdagang atau membuka lapak usaha di kawasan tersebut. Survey pendahuluan yang dilakukan oleh peneliti menggambarkan sedikitnya 500 pedagang berjualan setiap harinya dan hampir 2 (dua) kali lipat jumlahnya ketika hari Sabtu dan Minggu atau hari libur. Hal ini tentu saja mendorong Pemerintah Provinsi DKI Jakarta untuk mengambil kebijakan dalam penataan dan pemberdayaan pedagang kaki lima di Kawasan Kota Tua Jakarta agar keberadaan mereka tidak mengganggu kepentingan publik namun di sisi lain pemberdayaan ekonomi bagi para pedagang kaki lima juga dapat berjalan.

Keberadaan pedagang kaki lima di Kawasan Kota Tua akhir-akhir ini menjadi sorotan utama atas ketidakteraturan dan kenyamanan yang terjadi di Taman Fatahillah. Jumlahnya yang cenderung terus bertambah terlebih di akhir pekan dan hari libur yang diperkirakan mencapai ribuan orang. Sebagai public space area dan tidak berbayar menjadi salah satu penyebab ramainya pengunjung yang datang ke Taman Fatahillah, yang tentu saja hal ini diikuti dengan maraknya para pedagang kaki lima yang menjajakan barang dagangannya, baik yang menggunakan gerobak, dipikul, maupun bersepeda.

Kebijakan yang diambil oleh Pemerintah Provinsi DKI Jakarta mengacu pada Perda No. 8 Tahun 2007 Tentang Ketertiban Umum, Peraturan Gubernur No. 33 Tahun 2010 Tentang Pengaturan Tempat dan Pembinaan Usaha Mikro Pedagang Kaki Lima di Provinsi Daerah Khusus Ibukota Jakarta dan Keputusan Walikota Kota Administrasi Jakarta Barat Nomor 581 Tahun 2014 Tentang Penetapan Lokasi Sementara Usaha Mikro/Pedagang Kaki Lima di Kawasan Kota Tua.

Hasil dari implementasi kebijakan tersebut diharapkan sejalan dengan tujuan dikeluarkannya Peraturan Gubernur Nomor 36 Tahun 2014 tentang Rencana Induk Kawasan Kota Tua, bahwa Pembangunan kawasan Kota Tua diarahkan dengan visi mewujudkan kawasan Kota Tua sebagai kawasan cagar budaya yang memiliki nilai ekonomi yang tinggi sebagai kawasan wisata, bisnis, jasa dan perdagangan dengan tetap mempertahankan karakter dan nilai-nilai kesejarahan kawasan.

\section{B. PELAKSANAAN DAN METODE}

Penelitian ini menggunakan metode penelitian deskriptif dengan pendekatan kualitatif. Berdasarkan dimensi waktu, penelitian ini termasuk dalam cros sectional karena mengambil suatu bagian dari populasi dalam waktu tertentu. Lokasi penelitian 
beralamat di Jl. Taman Fatahillah, Kelurahan Pinangsia, Kecamatan Tamansari, Jakarta Barat. Waktu Penelitian dilaksanakan sejak Januari - Juli 2015. Sumber data yang digunakan adalah data primer dan data sekunder. Teknik pengumpulan data dilakukan dengan cara observasi dan wawancara.

Implementasi suatu kebijakan dapat dianalisis dengan mengunakan beberapa model implementasi kebijakan. Salah satu model implementasi kebijakan adalah model yang dikembangkan oleh Van Meter dan Van Horn (Evita dkk, 2013) yang disebut sebagai a model of the policy implementation process (model proses implementasi kebijakan). Model ini mencoba menghubungkan antara isu kebijakan dengan implementasi dan suatu model konseptual yang mempertalikan kebijakan dengan prestasi kerja (performance). Antara kebijakan dengan prestasi kerja dipisahkan oleh sejumlah variabel bebas (independent variable) yang saling berkaitan. Variabel-variabel bebas itu diantaranya; Ukuran dan tujuan kebijakan, sumber-sumber kebijakan, ciri-ciri atau sifat badan/instansi pelaksana, komunikasi antar organisasi terkait dan kegiatan-kegiatan pelaksanaan, sikap para pelaksana, dan lingkungan ekonomi, politik, dan sosial.

Merujuk pada Peraturan Gubernur DKI Jakarta No. 33 Tahun 2010, Pedagang Kaki Lima adalah "Kegiatan usaha jasa perdagangan yang menempati prasarana kota, fasilitas sosial dan fasilitas umum milik Pemerintah Daerah, tanah/lahan milik perorangan/badan yang telah mendapat izin dari Gubernur".

Dalam rangka membina Usaha Mikro Pedagang Kaki Lima sebagai pelayanan jasa perdagangan yang menyerap banyak tenaga kerja dan mencegah dampak negatif atas pemanfaatan prasarana kota, fasilitas sosial dan fasilitas umum lainnya, Pemerintah Provinsi DKI Jakarta mengeluarkan kebijakan dalam sebuah Peraturan Gubernur yang diikuti Keputusan Walikota Kota Administrasi Jakarta Barat Nomor 581 Tahun 2014 Tentang Penetapan Lokasi Sementara Usaha Mikro/Pedagang Kaki Lima di Kawasan Kota Tua.

Fokus utama dalam penelitian ini adalah implementasi kebijakan penataan pedagang kaki lima di kawasan kota Tua Jakarta. Secara teori, Merilee S. Grindle (Wibowo, 2008) mengatakan bahwa pada dasarnya (implementasi) kebijakan publik dapat dianalisis berdasarkan dua hal yaitu content (isi) dan context (kondisi sosial) kebijakan tersebut. Beberapa unsur content yang ikut mempengaruhi implementasi kebijakan publik adalah: (1) Interest affected atau kepentingan yang dipengaruhi (oleh kebijakan publik). (2) Type of benefits atau tipe manfaat yang dihasilkan. (3) Extent of change envisioned atau keluasan perubahan yang diharapkan. (4) Site of decision making atau posisi pembuat keputusan. (5) Program implementors atau pelaksana program. (6) Resources committed atau sumber daya, meliputi sumber daya maupun sumber daya non-manusia.

Ada 4 (empat) klaster yang disediakan oleh Pemerintah Provinsi DKI Jakarta melalui Suku Dinas UMKM Jakarta Barat, antara lain; Klaster 1 lorong antara Kantor Imigrasi dengan Gedung Pos, Klaster 2 lorong antara Gedung Pos dan Gedung Jasindo, Klaster 3 lorong Virgin dan Klaster 4 di sepanjang jalan Kalibesar Timur. Di luar 4 (empat) klaster tersebut Pemerintah Provinsi DKI menyatakan sebagai tempat yang dilarang untuk berdagang atau berusaha. 


\section{C.HASIL DAN PEMBAHASAN}

\section{Kebijakan Penataan Pedagang Kaki Lima di Kawasan Kota Tua Jakarta}

Kota Tua Jakarta terletak di Kelurahan Pinangsia Kecamatan Tamansari Kota Administrasi Jakarta Barat. Sisi Utara berbatasan dengan Pasar Ikan, Pelabuhan Sunda Kalapa dan Laut Jawa, Sisi Selatan berbatasan dengan Jalan Jembatan Batu dan Jalan Asemka, sebelah Barat berbatasan dengan Kali Krukut dan sebelah Timur berbatasan dengan Kali Ciliwung.

Kebijakan penataan dan pembinaan pedagang kaki lima di Kawasan Kota Tua Jakarta mengacu pada Peraturan Daerah Nomor 8 Tahun 2007 tentang Ketertiban Umum pada Pasal 25 ayat 1 menyatakan bahwa "Gubernur menunjuk/menetapkan bagian-bagian jalan/trotoar dan tempattempat kepentingan umum lainnya sebagai tempat usaha pedagang kaki lima". Selanjutnya di ayat 2 menyatakan bahwa "Setiap orang atau badan dilarang berdagang, berusaha di bagian jalan/trotoar, halte, jembatan penyebrangan orang dan tempattempat untuk kepentingan umum lainnya di luar ketentuan sebagaimana dimaksud pada ayat (1)."

Untuk memperoleh izin lokasi usaha, pedagang kaki lima harus mengikuti ketentuan Pasal 11 ayat (2) Peraturan Gubernur Nomor 33 Tahun 2010 yang menyatakan "Untuk memperoleh izin sebagaimana dimaksud pada ayat (1) Usaha Mikro Pedagang Kaki Lima yang bersangkutan harus mengajukan permohonan secara tertulis kepada Kepala Suku Dinas Koperasi Usaha Mikro, Kecil Menengah dan Perdagangan setempat dengan melampirkan persyaratan (a) Foto Copy KTP dan KK, (b) Profil Usaha Mikro, (c) Surat Pernyataan belum pernah mendapat fasilitas lokasi
Walikota Jakarta Barat telah mengeluarkan Surat Keputusan Nomor 581 Tahun 2014 tentang Penetapan Lokasi Sementara Usaha Mikro/Pedagang Kaki Lima Di Kawasan Kota Tua Administrasi Jakarta Barat. Dalam Surat Keputusan tersebut, para pedagang telah dikelompokkan ke dalam 4 (empat) klaster atau tempat lokasi usaha sementara dengan total pedagang sejumlah 415 pedagang yang beroperasi pada pukul 18.00-24.00.

Proses kebijakan penataan pedagang kaki lima di Kota Tua melibatkan banyak stakeholders, seperti Dinas KUMM DKI Jakarta, Suku Dinas KUKM Jakarta Barat, Kecamatan Taman Sari, Satpol PP, Kelurahan Pinangsia, RW dan dari pihak swasta PT Pembangunan Kota Tua Jakarta/ JOTRC (Jakarta Old Town Revitalization Corporation) dan JEFORAH (Jakarta Endowment For Art and Heritage), yang mendapat mandat dari Gubernur DKI Jakarta untuk melaksanakan Revitalisasi Kota Tua Jakarta.

\section{Implementasi Kebijakan Penataan Pedagang Kaki Lima di Kawasan Kota Tua Jakarta}

Implementasi kebijakan penataan pedagang kaki lima di kawasan Kota Tua merupakan sesuatu yang penting, bahkan mungkin lebih penting daripada pembuatan kebijakannya itu sendiri. Dalam penelitian ini, cara mencapai sasaran atau tujuan dari kebijakan penataan pedagang kaki lima ini yang disebut dengan implementasi.

\section{Analisis Implementasi Kebijakan Penataan Pedagang Kaki Lima di Kawasan Kota Tua Jakarta}

Menurut Merilee S. Grindle mengatakan bahwa pada dasarnya (implementasi) kebijakan publik dapat 
dianalisis berdasarkan dua hal yaitu content (isi) dan context (kondisi sosial) kebijakan tersebut (Wibowo, 2008). Beberapa unsur content yang ikut mempengaruhi implementasi kebijakan publik antara lain; Interest affected atau kepentingan yang dipengaruhi (oleh kebijakan publik), Type of benefits atau tipe manfaat yang dihasilkan, Extent of change envisioned atau keluasan perubahan yang diharapkan, Site of decision making atau posisi pembuat keputusan, Program implementors atau pelaksana program dan yang terakhir Resources committed atau sumber daya, meliputi sumber daya maupun sumber daya nonmanusia.

\section{Kepentingan yang dipengaruhi oleh kebijakan}

Implementasi kebijakan yang dijalankan oleh Pmprov DKI Jakarta terkait penataan pedagang kaki lima di kawasan Kota Tua tentunya berdampak secara langsung maupun tidak langsung kepada beberapa pihak (stakeholders).

Pihak yang paling utama merasakan dampaknya adalah pedagang kaki lima itu sendiri. 415 pedagang kaki lima yang terseleksi masuk dalam binaan koperasi tentunya menyambut baik kebijakan ini, hal ini dikarenakan adanya kepastian berusaha bagi mereka baik itu tempat maupun waktu berdagang. Sementara bagi pedagang yang tidak masuk dalam koperasi, kebijakan ini praktis memaksa mereka harus meninggalkan lapak usahanya saat ini jika tidak ingin ditertibkan oleh Satpol PP. Untuk hal ini Pemprov DKI dengan tegas akan menertibkan pedagang kaki liar yang berdagang di luar waktu dan tempat yang telah ditetapkan.

Pihak berikutnya adalah pengunjung yang datang ke kawasan Kota Tua. Sebelumnya keberadaan pedagang kaki lima di Taman Fatahillah cukup mengganggu ketertiban dan kenyamanan pengunjung Kota Tua. Hampir seluruh area Taman Fatahillah dipadati oleh pedagang kaki lima terlebih ketika malam sabtu dan minggu atau hari libur. Dengan dilaksanakannya kebijakan penataan ini, Taman Fatahillah saat ini lebih tertib dan nyaman.

Sebagai bagian dari stakeholders yang ada di kawasan Kota Tua, Beberapa kantor dan perusahaan yang ada di sepanjang Jalan Kali Besar Timur juga mendukung pelaksanaan penataan pedagang kaki lima ini, namun mereka berharap agar tetap ada akses jalan yang diberikan bagi mereka untuk keluar-masuk. Hal ini terjadi dikarenakan, ketika jam kerja kantor, mobil atau kendaraan operasional dan tamu mereka parkir di sepanjang jalan Kali Besar Timur yang sore harinya tempat parkir dan akses jalannya berganti menjadi lapak berdagang para pedagang kaki lima.

\section{Type of benefits atau tipe manfaat yang dihasilkan}

Secara umum, tujuan penataan ini dimaksudkan agar Kota Tua Jakarta lebih tertata rapih, nyaman dan aman. Paralel dengan maksud tersebut kebijakan ini juga bagian yang tidak terpisahkan dari program Revitalisasi Kota Tua Jakarta yang dicanangkan oleh Gubernur DKI Jakarta pada tanggal 13 Maret 2014. Kota Tua juga telah didaftarkan dan masuk dalam tentative list UNESCO World Heritage Site.

\section{Extent of change envisioned atau keluasan perubahan yang diharapkan}

Implementasi kebjakan penataan pedagang kaki lima ini memiliki dampak yang cukup luas dan tentunya membutuhkan waktu yang tidak sebentar. Kebijakan pemanfaatan fasilitas umum oleh pedagang kaki lima, tentunya bersinggungan dengan adanya perubahan kebijakan yang ada di SKPD (Satuan Kerja Perangkat Daerah) yang 
lain, sebagai contoh tempat yang diizinkan oleh Pemerintah Provinsi DKI Jakarta untuk berdagang merupakan lahan parkir yang memang keberadaannya sangat terbatas di kawasan Kota Tua. Akibatnya, perlu ditetapkan kembali titik-titik mana saja yang diperkenankan menjadi lahan parkir pengganti. Belum lagi dari Dinas Pertamanan untuk menata pohon-pohon yang menghalangi tenda-tenda para pedagang ketika akan didirikan. Bertambahnya debit sampah yang ditimbulkan dari produk dagangan mereka juga akan menjadi program kerja tambahan bagi Dinas Kebersihan. Sehingga implementasi kebijakan ini secara langsung akan mendorong perubahan yang menyeluruh di kawasan Kota Tua Jakarta.

Keberadaan pedagang kaki lima di kalaster-klaster yang ada merupakan lokasi sementara (loksem) yang jangka waktunya hanya 1 (satu) tahun, sehingga keberadaan klaster tersebut sewaktu-waktu diperlukan oleh Pemerintah Provinsi DKI Jakarta dapat digunakan tanpa harus memberikan kompensasi apapun kepada para pedagang.

\section{Site of Decision Making atau Posisi Pembuat Keputusan}

Hirarki pembuat kebijakan penataan pedagang kaki lima di kawasan Kota Tua berdasar pada Peraturan Gubernur DKI Jakarta dan dilaksanakan oleh wilayah serta Satuan Kerja Perangkat Daerah (SKPD) terkait. Oleh karenanya, koordinasi pelaksanaan kebijakan ini menjadi satu hal yang mutlak untuk dilaksanakan. Sejalan dengan program revitalissi Kota Tua, koordinasi implementasi penataan pedagang kaki lima dimonitor langsung oleh Deputi Gubernur Bidang Budaya dan Pariwisata, sehingga implikasi atas kebijakan ini pun dapat diselesaikan secara baik dengan melibatkan unsur SKPD lainnya serta pihak swasta.

\section{Program implementors atau pelaksana program}

Pelaksana kebijakan ini melibatkan banyak instansi baik pemerintah maupun swasta antara lain Dinas Koperasi, UMKM dan Perdagangan, Dinas Pariwisata dan Kebudayaan, Dinas Perhubungan, Dinas Pertamanan dan Pemakaman, Dinas Kebersihan, Satpol PP, Dinas Perindustrian dan Energi, Walikota Jakarta Barat, UPK Kota Tua, Camat, Lurah, Polsek, Koramil, PLN, serta PT Pembangunan Kota Tua Jakarta.

Banyaknya jumlah instansi yang terlibat dalam implementasi kebijakan penataan pedagang kaki lima di kawasan Kota Tua memiliki keuntungan tersendiri terutama terkait akan dampak yang ditimbulkan dari kebijakan tersebut.

\section{Resources Committed atau Sumber Daya \\ Salah satu indikator dari} keberhasilan implementasi kebijakan penataan pedagang kaki lima di kawasan Kota Tua adalah sumber daya yang dimiliki oleh setiap instansi pelaksana, baik itu sumber daya manusia maupun non-manusia.

Secara umum, awalnya pedagang kaki lima sebagai kelompok target kebijakan ini merespon negatif penataan yang dilakukan oleh Pemerintah Provinsi DKI Jakarta. Bagi mereka sebagus apapun tujuan pemerintah, jika mereka tidak lagi dapat berdagang maka kebijakan tersebut menjadi kebijakan yang tidak diinginkan.

\section{PENUTUP}

\section{Simpulan}

Kebijakan penataan pedagang kaki lima pada kawasan Kota Tua Jakarta merupakan kebijakan dalam rangka merevitalisasi Kota Tua Jakarta serta menjadikan Kota Tua sebagai UNESCO 
World Heritage Site. Kebijakan ini mengacu pada Peraturan Daerah Nomor 8 Tahun 2007 tentang Ketertiban Umum dan dalam hal pengaturan lokasi tempat usaha kebijakannya mengacu pada Peraturan Gubernur No 33 Tahun 2010. Pedagang Kaki Lima Kawasan Kota Tua bearada dalam wilayah Kota Administrasi Jakarta Barat.

Implementasi kebijakan penataan pedagang kaki lima di Kota Tua melibatkan banyak stakeholders, seperti Dinas Koperasi, UMKM dan Perdagangan, Dinas Pariwisata dan Kebudayaan, Dinas Perhubungan, Dinas Pertamanan dan Pemakaman, Dinas Kebersihan, Satpol PP, Dinas Perindustrian dan Energi, Walikota Jakarta Barat, UPK Kota Tua, Camat, Lurah, Polsek, Koramil, PLN, serta PT Pembangunan Kota Tua Jakarta. Sehingga dapat dikatakan bahwa kebijakan ini telah berhasil dan merupakan successful implementation.

Dalam implementasinya kebijakan penataan pedagang kaki lima di Kawasan Kota Tua Jakarta dihadapkan pada beberapa kendala, antara lain; Pengendalian jumlah pedagang liar yang terus bertambah, kedisiplinan para pedagang anggota koperasi serta sarana dan prasarana yang kurang memadai.

\section{Saran}

Kebijakan yang dilaksanakan saat ini menempatkan pedagang kaki lima pada lokasi sementara, sehingga perlu dipikirkan lagi keberlanjutannya mengingat Kota Tua sedang diajukan menjadi Cagar Budaya Nasional dan menuju UNESCO World Heritage Site.

Penegakkan Peraturan Daerah Nomor 8 Tahun 2007 tentang Ketertiban Umum oleh Satpol PP terkait pedagang kaki lima liar yang masih mencoba berjualan agar lebih ditingkatkan sehingga tidak menimbulkan kecemburuan sosial bagi pedagang anggota koperasi yang telah direlokasi.
Penyediaan sarana dan prasarana yang lebih baik lagi agar pedagang maupun pengunjung dapat lebih nyaman ketika berkunjung ke Kota Tua Jakarta.

\section{Ucapan Terima Kasih}

Penulis mengucapkan terima kasih kepada Pemerintah Provinsi DKI Jakarta dalam hal ini Dinas Koperasi dan UMKM, Suku Dinas UMKM Jakarta Barat serta Dinas Pariwisata dan Kebudayaan, PT Pembangunan Kota Tua Jakarta/JOTRC (Jakarta Old Town Revitalization Corporation, JEFORAH (Jakarta Endowment Fund and Heritage), Pengurus Koperasi PENAWASKATA (Pedagang Binaan Kawasan Kota Tua Jakarta) atas terlaksananya penelitan ini serta Jurnal Pemberdayaan Masyarakat (JPM) Universitas Kanjuruhan Malang (UNIKAMA) yang telah mempublikasikan penelitian ini.

\section{E. DAFTAR PUSTAKA}

Dwidjowijoto dan Nugroho R. 2006. Kebijakan Publik Untuk NegaraNegara Berkembang, PT. Gramedia, Jakarta.

Evita E. Supriyono B dan Hanafi I. 2013. Implementasi Kebijakan Penataan Pedagang Kaki Lima (Studi pada Batu Tourism Center di Kota Batu). Jurnal Administrasi Publik (JAP) Vol. 1, No. 5: Universitas Brawijaya Malang.

Peraturan Daerah Provinsi Daerah Khusus Ibukota Jakarta Nomor 8 Tahun 2007 Tentang Ketertiban Umum. 
Peraturan Gubernur No. 33 Tahun 2010 Tentang Pengaturan Tempat dan Pembinaan Usaha Mikro Pedagang Kaki Lima di Provinsi Daerah Khusus Ibukota Jakarta.

Salmina GW. 2004. Studi Kasus: Pengaruh Keberadaan Pedagang Kaki Lima Terhadap Jumlah Pengunjung Taman Kota Di Medan. Jurnal Teknik SIMETRIKA, Vol, 3 No. 3, Universitas Sumatera Utara, Medan.

Surat Keputusan Walikota Kota Administrasi Jakarta Barat Nomor 581 Tahun 2014 Tentang Penetapan Lokasi Sementara Usaha Mikro/Pedagang Kaki Lima Di Kawasan Kota Tua.

Wibowo dan Mardian. 2006. Studi Implementasi Kebijakan Penanganan Gelandangan di Kota Jakarta Timur, Tesis, FISIP UI. 